\title{
A conversation with Gregg Semenza
}

$I_{\text {ss }}$ a truth universally acknowledged that we need air to breathe, function, and thrive. But, how do we sense oxygen and respond to a lack of it? Gregg Semenza of Johns Hopkins Medicine has made this question his life's work. For the discovery of the hypoxia-inducible factor, HIF, Semenza (Figure 1) has been awarded recently with the Lasker Prize for Basic Medical Research. See the full interview on the JCI website at http://jci.org/videos/cgms.

JCI: What were you like as a kid?

Semenza: I grew up in Tarrytown, New York, going to Washington Irving Junior High School and Sleepy Hollow High School. I grew up with two brothers and two sisters. My mom was an elementary school teacher and my dad worked as a social worker at a hospital in New York City. It was a chaotic environment. Basically, it was in the morning, "Get out of the house and we'll see you at dinner time." We had pretty much free rein in terms of getting around on our own and entertaining ourselves.

JCI: Were you a good student?

Semenza: I had an inflection point when I was in the third grade and we were supposed to read a book and then give an oral report. I hadn't read the book, so that made it very difficult for me to answer the questions. When it was my turn, it didn't take my teacher very long to figure out that I hadn't read the book. She was very kind and said, "Well, maybe you'd be better if you go and read the book and then we can talk about it after that." As a result of that, I became a voracious reader.

JCI: When did your interest in science develop?

Semenza: That was high school. I had this fantastic biology teacher in freshman biology in high school, Rose Nelson, who was an unbelievably talented, beautiful person who was able to transmit the beauty of science and the thrill of scientific discovery. She had a PhD and had worked at Woods Hole, so she knew what research was and that was my inspiration. I had her as a freshman for biology and then as a senior for AP biology, when it was genet- ics within biology that I got really excited about. With her help, I was able to enroll in an NSF-sponsored summer program at the Boyce Thompson Institute for plant research, which at that time was in Yonkers, New York. It was really my first exposure to research and to experiments.

JCI: When did you decide to train to be a medical doctor?

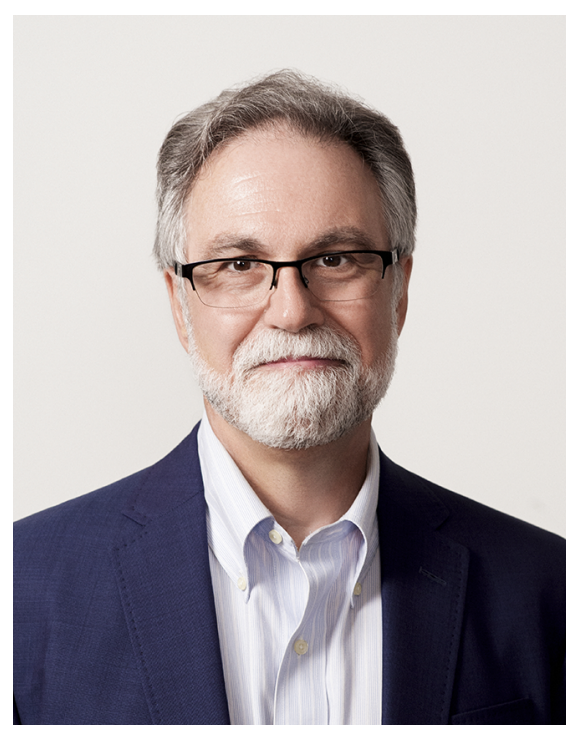

Figure 1. Gregg Semenza on September 22, 2016 in New York City. Image credit: Alexey Levchenko.

Semenza: That wasn't until my junior year in college. I was interested in genetics and thought I would go to graduate school and study that. While I was an undergrad, a family that we were friends with had a child born with Down Syndrome, and that made me interested in medical genetics. I decided that I would try to get into an MD$\mathrm{PhD}$ program and study genetics, and also take care of people with genetic disorders.

JCI: What did you choose to study for the $\mathrm{PhD}$ part of your MD-PhD?

Semenza: The PhD story was a rocky road. I was in a lab the first year, a lab where I was the first graduate student in the lab, maybe not a really good choice. The project that I had was something that was very ambitious, maybe not a good choice. I just got to the point where I felt that I didn't see this really working out. So, I switched to a lab at Children's Hospital of Philadelphia that was studying $\beta$-thalassemia, which at that time was the first disease where the mutations that caused the disease were being identified (in the $\beta$-globin gene). I was tasked with studying an unusual family, where one of the alleles was a silent carrier.

Normally, you can tell from looking at the blood cells whether someone is a carrier. In this case, it was the father who was an obligate carrier, as he had two affected children but you couldn't tell he was a carrier. It was suggested that the mutation was in some way different; this was going to be my project. The idea was that you take the blood, isolate the DNA, make a library, pull out the $\beta$-globin gene, and sequence it. I did all that and at the end of one year, I got the sequence, and the mutation was the exact same mutation as the previous study, which meant that somehow the clone had become contaminated, and the whole thing had been for nothing. So now I was going to have to start over the third time. I went back, started over again; things went smoothly because technically I'd already done it, and we went through the project and got an answer.

JCI: How did your interest evolve from thalassemia to hypoxia?

Semenza: I then went to Hopkins for a Pediatric Genetics fellowship. I was interested in regulation of gene expression, developmental regulation, and, from a technical standpoint, I was interested in transgenic mice. I was attracted to Hopkins because Haig Kazazian and Stylianos Antonarakis were there as leaders in finding the molecular basis of $\beta$-thalassemia, collaborating with Stuart Orkin at Harvard to identify the mutations and their functional significance. By the time I got there, they had shifted from studying $\beta$-thalassemia to hemophilia and mutations in the factor VIII gene.

I called up Chuck Shoemaker, who was the scientist they had obtained their factor VIII clones from at the Genetics Institute in Cambridge. He offered them gladly, and said, “...there's this other gene you might want to consider called EPO [erythropoietin]." EPO is expressed in the fetal liver, 
and then in the adult its expression shifts to the kidney, so I thought it would be interesting to identify the DNA sequences in the gene responsible for expression in the different tissues. We put different fragments of human DNA spanning the EPO gene into mice and then looked to see if and where the gene was expressed.

The really interesting thing about the gene was that it was regulated by oxygen. That took me a few years to figure out. We had to figure out where the key sequences were located and, of course normally people will look in the promoter region, the $5^{\prime}$ end of the gene, but I'd isolated nuclei from the liver of one of our transgenic mice and there was very strong DNA hypersensitive site within the human EPO transgene. But rather than being at the $5^{\prime}$ end of the gene, it was actually in the $3^{\prime}$ flanking sequence of the gene, which was kind of unusual.

But that's what the data said, so we showed that we could take a piece of DNA that encompassed that site and put it into a reporter plasmid, put the plasmid into a human cell line where EPO expression was induced by hypoxia, and now the reporter gene would be induced by hypoxia. We simply made smaller and smaller fragments to identify the minimal sequence that was required, and we ended up getting down to 50 base pairs or 33 base pairs. And then, we mutated individual nucleotides and found mutations that completely eliminated function. We suspected that there was a very important factor, which was binding to that sequence and was responsible for turning on the gene. And so, we tried to find the protein that was the key factor for turning on the EPO gene.

JCI: At this point, you're a young faculty member with your first great postdoc, Guang Wang.

Semenza: Every experiment that he did, from a technical point of view, worked and was beautiful. By that time, I had started trying to perform assays to look for a nuclear protein that would bind to the hypoxia response element, and this was a real trial and error process and Guang took that up.

The problem is that the binding of proteins to DNA is very idiosyncratic. Lots of nuclear proteins are positively charged, and they'll bind to negatively charged DNA, so you'd have to worry about non-specific binding. But, if you compete that off too much, you won't see the specific binding. So, you have to figure out what conditions will allow binding and then we were looking for something that we hoped would be present in the nuclei from the hypoxic cells, and absent from the cells that were not hypoxic. The idea was to see some kind of faint signal that you could then try to optimize. Guang would do several of these experiments a day, and had this stack of blots with negative results on his desk. I was thumbing through them one day, and I came across this one gel where there seemed to be a faint band in the hypoxic lane. I got all excited and said, "Did you see this? Did you see this?" After optimizing the assay in a very short period of time, he generated really strong definitive results of a binding activity that we called hypoxia-inducible factor 1 .

JCI: HIF turned out to be a dimer.

Semenza: Well, that assay had gave us a DNA binding activity, but of course we wanted to actually isolate a protein and the DNA sequences that coded for the protein. I was influenced by Steve McKnight, who had developed a technique for expressing proteins in bacteriophage. We tried to use this approach, and made a library from hypoxic cells, and screened with the binding site DNA sequence as probe because we had done an experiment that we thought indicated that there was a single protein that would be recognized by the probe. We screened millions and millions of clones and got no positive result.

At some point you have to decide, "Do we keep trying or do we stop?" Or, maybe try some other alternative experimental strategy, which of course was biochemical purification. At that time we were a lab that utilized molecular genetics techniques - not biochemistry - we didn't even own a fraction collector. Fortunately, Tom Kelly's lab was right across the street, and his lab had been one of the first labs to purify a protein based on its DNA binding activity. We ended up purifying the protein from 100 liters of HeLa cells in suspension culture and were able to purify enough of the protein by DNA affinity chromatography to get some sequence data. From prior experiments we had learned that the protein did not stay on DNA very long. It went on and it came off very rapidly, which is the worst property you could possibly have if you were doing affinity purification.
JCI: Was that finally your moment for champagne?

Semenza: To get the cDNAs, yeah, that was a big moment because it enabled us to analyze mRNA expression and generate antibodies to look at protein expression, and we also shared those reagents with other labs so that they could do the same and that really opened the field.

JCI: Is there anything that HIF doesn't touch?

Semenza: Well, then you have to ask is there any biological process where oxygen is not playing some sort of a role? And the answer is that oxygen is so fundamental to life that there's tremendous crosstalk, and so HIF really is a nexus for many different inputs and outputs.

JCI: You've done this body of work without thinking about winning prizes, but you've won the Wiley Prize, the ASCI Korsmeyer Award, the Gairdner, and now the Lasker Prize for Basic Medical Research award. What do these kinds of recognitions mean for you?

Semenza: I think it's really great for people to get a sense of research and to see how fundamental discoveries can lead to very practical results, ultimately. For the public to get some sense of what science is like, and when you can make that connection to the diseases that most people end up being affected by heart disease, cancer - the public can really appreciate the impact of scientific research. We started with a very focused question, a simple question and that's the way science works. It's the serendipity that makes it so exciting because you never know where things are going to lead. And you think you know, but most of the time, at least for me, it turns out that the hypothesis is wrong - but it doesn't matter, you found out something really interesting. And that's what makes science so exciting. Because you just never know where it's going to lead.

JCI: If you had to do it all over again, you couldn't be an MD or a PhD scientist, what else do you think could have kept you this passionate as a career?

Semenza: The one thing I pretended when I was younger was that I was an FBI agent. Investigating crimes, being a detective, it's like being a scientist, right?

Ushma S. Neill 